\title{
Influence of Postharvest Storage Management Strategies on Postharvest Cereal Loss in Wikililye Location of Kitui County
}

\author{
Wanjiku A. Njoki* , Harrison M. K. Maithya, Felix N. Kioli \\ Department of Sociology and Anthropology, South Eastern Kenya University, Kitui, Kenya \\ *Corresponding author: wanjikuagnes40@yahoo.com
}

\begin{abstract}
The study determined the storage management strategies influence on postharvest cereal loss in Wikililye Location of Kitui County. Quantitative data were collected using a structured questionnaire on343 households selected through systematic sampling method using population proportionate to size approach to select the actual number of respondents for each village. Focus Group Discussions and Key Informants purposively sampled were used to obtain qualitative data. The data were subjected to descriptive statistics and presented using tables and verbatim narratives. The findings revealed that majority (62\%) of the respondents experienced postharvest cereal loss while a significant number (34\%) did not. The study sought to determine the mode of storage currently utilized by the respondents and the findings indicated the majority (72\%) utilized gunny bags. Knowledge of any form of improved storage facilities showed that majority (77\%) of the respondents were aware of improved storage methods but only $35 \%$ did not experience loss. On the use of improved storage system to reduce postharvest cereal loss the study revealed that an overwhelming majority (92\%) of the households utilize traditional mode of storage and experienced cereal loss. Only (8\%) of the respondents had adopted improved methods and majority (76\%) of those who had adopted did not experience cereal loss. Awareness of improved storage facilities did not result in reduced postharvest cereal loss. However, a significant reduction of postharvest loss was reported by the respondents who utilized improved storage facilities. Storage facilities are thus significant determinants of household postharvest cereal loss. The study recommends that in addition to increasing awareness of the existence of improved storage facilities, they should be made available and affordable or economically attainable to small scale farmers and households.
\end{abstract}

Keywords: postharvest cereal loss, households, Wikililye location, storage, awareness, attainability'

Cite This Article: Wanjiku A. Njoki, Harrison M. K. Maithya, and Felix N. Kioli, "Influence of Postharvest Storage Management Strategies on Postharvest Cereal Loss in Wikililye Location of Kitui County.” Journal of Food Security, vol. 6, no. 1 (2018): 26-30. doi: 10.12691/jfs-6-1-3.

\section{Introduction}

The issue of postharvest cereal loss caused by factors such as poor postharvest storage facilities and strategies is an important factor in combating hunger, raising income earnings, and improving food security in the world's poorest countries [1]. Storage plays a critical role in agriculture mainly because production is seasonal while demands for agricultural commodities are spread through the year. Numerous studies indicate that maximum losses happen during storage operation [2,3,4]. In Asia, mud bins and pots, and plastic containers are common storage structures utilized [5]. In developing countries studies show that even though people try to make use of cereals produced, a significant amount of cereals is lost due to poor storage facilities with research indicating that between 50 and $60 \%$ of the grains are stored in the traditional structures such as simple granaries constructed from locally available materials [5], which cannot guarantee protection of cereals against pests for a long time [6]. The same situation is reported in Africa where farmers experiences recurrent heavy post harvest cereal losses [7]. Much of these losses are because of poor storage infrastructure, for example, the use of traditional wooden cribs, which facilitate the growth of pests such as the smaller and larger grain borers. In East Africa, majority of the farmers rely on traditional storage systems, which are not effective resulting in postharvest cereal losses. In Nigeria farmers use the traditional methods of storage such as storing maize over the fire places, sacks and tins, which are not effective occasioning postharvest loss of agricultural produce [8]. Similarly in Ghana, farmers experience very high storage losses ranging between 30-40 percent [9]. Poor storage methods results in invasion of the cereal by destructive pests of stored maize especially the larger grain borer, which turns maize into powder, causing high losses to farmers and threatening their food supply and income [9]. Also in Ethiopia storage facilities used by farmers includes traditional grain stores such as grain pits, bags (made of 
polyethylene, sisal or goat skin), earth pots and some others, which increased the rate of cereal loss [10]. In Uganda studies show that the predominant storage technologies utilized by households are polypropylene bags. In Kenya, maize is the most important cereal and staple food for over $90 \%$ of the population [11]. Maize accounts for more than $20 \%$ of all agricultural produce and $25 \%$ of agricultural employment [12]. However, grain losses contribute to food insecurity and low farmers' income [13]. In Kitui county postharvest losses during storage accounted for up to $20-30 \%$ within 6 months of harvest due to poor storage facilities [14]. In Wikililye Location, the type of storage utilized and the influence of the facilities on postharvest cereal loss is not well documented. Available literature suggests that the type of storage practices influenced postharvest cereal loss. It is also evident that majority of the farmers use traditional storage facilities. The study, therefore, sought to establish the influence of storage facilities used by farmers in Wikililye Location on postharvest cereal loss.

The lack of awareness of good post harvest practices and technology by farmers has been identified as one of the challenges to be dealt with if a meaningful post harvest losses of cereals reduction is to be achieved [15,16,17]. However, different studies have different views on the influence of awareness of better storage practices on post harvest cereal losses. Different factors play different roles [18]. These include non-availability of the technologies individuals are awareness of, lack of economic incentives to store and better protect their food, and non-cost effectiveness of technologies. In different agro-ecological zones of Kenya, training on grain storage and protection technologies did not necessarily result in lower post harvest cereal storage losses as farmers who received training incurred similar magnitude of post harvest losses as those farmers who did not receive the training [13]. In Tanzania awareness creation plays a vital role in the implementation of improved technologies, [19]. Availability of improved technologies alone may not be effective unless communities are sensitized and the level of awareness enhanced, which in turn affects adoption and may possibly result into reduction of postharvest cereal loss. Better awareness provides additional new meaning and interpretation that changes events, lives, or experiences, which have implication on farmers' wellbeing from production all through to postharvest activities that contribute to cereal losses. The present study, therefore, examines how farmers' awareness of improved storage facilities influence postharvest cereal loss and the lives of the farmers in order to alleviate poverty in the study area in particular and generally in Kenya.

Adoption of new technologies to prevent postharvest losses has been a policy to curb losses. Training in improved handling and storage practices, the use of hermetically sealed bags and household's metallic silos are seen as promising practices in the reduction of postharvest cereal loss [20]. However, the potential gain from adopting these technologies has been faced with challenges particularly in the rural areas and specifically among small scale farmers [21]. This is despite modern methods such as hermetic bags being easy to use, elimination of pesticide use, favorable costs, and modest infrastructure requirements being some of the additional advantages that make them attractive [22]. Thus postharvest technologies can contribute to food security in multiple of ways [23]. They can reduce postharvest loss, thereby increasing the amount of food available for consumption by farmers and poor rural and urban consumers. Though the adoption of improved storage system is seen as a way of reducing postharvest losses the underlying factors such as availability and affordability hinders this. Some farmers who have already adopted report decreased losses whereas other farmers face challenges in the process of adoption. This paper explores the situation in Kitui County, specifically in Wikililye Location since there is no documented information regarding the same.

\section{Materials and Methods}

\subsection{Study Area}

The present study on which this paper is based was carried out in Wikililye Location of Kitui County, which lies between latitudes $0^{\circ} 10^{\prime}$ and $3^{\circ} 0^{\prime}$ 'South and longitudes $37^{\circ} 50^{\prime}$ and $39^{\circ} 0^{\prime}$ East. It is located in Mulango Ward in the Central Division of Kitui County, which covers an area of 809 square kms and it borders Kisasi to the South, Nzambani to the North East, Mbitini to the East, Kwa Vonza/Yattato the West and Kyangwithya West to the North West.

\subsection{Study Population}

According to Kenya National Bureau of Statistics [24], Wikililye Location has a population of 11,851 people with a total of 30 villages. The total number of households in the location is 3,149 . In the current study, the target population was adult male or female household heads.

\subsection{Sample Size}

The sample size was derived using Raosoft software with a 95\% confidence level and a margin error of $5 \%$. The sample size was 343 households. The study targeted household heads but where they were absent the person immediately after him/her was interviewed and where none was available, the interviewer moved to the next household to cater for the absent one.

\subsection{Sampling Procedure}

The study employed systematic sampling technique to select 343 households and utilized population proportionate to size approach to select the actual number for each identified village. A sampling frame comprising a complete list of all the households (study population) in each village was first compiled. In order to identify the exact household the $\mathrm{K}^{\text {th }}$ number was calculated by dividing the number of households for each village divided by the sample size obtained for the particular village. To cater for gender representation, household heads or persons immediately after the household heads were interviewed and were alternated by gender where applicable. 


\subsection{Data Collection Methods}

The study utilized a mixed method approach where both qualitative and quantitative methods of data collection were utilized. These were intended to provide a comprehensive understanding of the postharvest cereal management strategies and thus offer a more complete picture of the findings. Questionnaires were used to generate quantitative data while focus group discussions and key informant interviews generated qualitative data.

\section{Results and Discussions}

\subsection{Current form of Storage and Households Postharvest Cereal Loss}

Table 1 reveals that majority (72\%) of the respondents utilized gunny bags while a small percentage (15\%) used sisal sacks as the form of storage. Respondents who adopted improved storage system, the hermetic bags were few (7\%). It was also noted that $6 \%$ of the respondents used other forms of storage mainly utaa, which is a kind of a rack made of wooden sticks. The findings of the study are in consonance with the findings of a study in Uganda, which reported that $71 \%$ of the households use polypropylene bags with traditional and improved granaries being utilized by only $8 \%$ while others use offfarm facilities. Only $1 \%$ of the sampled respondents in the Uganda study utilized the hermetic (airtight) technology [25]. The findings of the current study further confirm findings of another study in Kenya, which revealed that the use of bags such as polypropylene or sisal for storage of shelled maize were the most common storage practices [26]. However, the majority (88\%) of those who had adopted the improved storage methods reported not experiencing post harvest cereal loss. Clearly, poor storage contributes to post harvest cereal losses. Field observations in the current study showed that the forms of storage used by respondents were not effective in preventing postharvest cereal loss. Some households stored their cereals on cemented floor in a corner inside the main house. Other studies have made similar observations that the traditional storage systems are prone to invasion by agents of stored food losses including pests and rodents [27]. In Amuria and Katawi Districts of Uganda, heavy postharvest cereal losses were reported to have been caused by poor storage structures [28]. And in Tanzania where farmers use as high as $40 \%$ traditional storage structures, postharvest losses of maize were found to range from 20 to $30 \%$ [29]. The findings of the current study are in consonance with earlier studies in Kenya [26].

Table 1. Current form of storage and post harvest cereal loss

\begin{tabular}{ccccccc}
\hline \multirow{2}{*}{$\begin{array}{c}\text { Distribution by } \\
\text { storage system used }\end{array}$} & Frequency & Percent & \multicolumn{2}{c}{$\begin{array}{c}\text { Lereal } \\
\text { Loss }\end{array}$} & \multicolumn{3}{c}{ No cereal } \\
\cline { 3 - 6 } & & & F & $\%$ & $\mathrm{~F}$ & $\%$ \\
\cline { 5 - 7 } Gunny bags & 251 & 72 & 166 & 66 & 85 & 34 \\
Sisal sacks & 53 & 15 & 43 & 81 & 10 & 19 \\
$\begin{array}{c}\text { Improved storage } \\
\text { bags }\end{array}$ & 25 & 7 & 3 & 12 & 22 & 88 \\
$\begin{array}{c}\text { Others including } \\
\text { Utaa }\end{array}$ & 22 & 6 & 8 & 36 & 14 & 64 \\
\hline Total & 351 & 100 & & & & \\
\hline
\end{tabular}

Source: Field survey data (2017)

\subsection{Awareness of Improved Storage System Influence on Households' Postharvest Cereal Loss}

Table 2 presents findings on awareness of improved storage system and household postharvest cereal loss. It shows that $77 \%$ of the study respondents were aware of the existence of improved storage technologies while 33\% were not. Awareness of improved storage technology is slightly higher in this study compared to a study in Tanzania, which found that only 55\% of the respondents were aware of modern storage systems [30]. To further establish the influence of awareness of improved storage systems on post harvest loss of cereals, descriptive analysis carried out indicated that a significant number (65\%) of the households respondents that had knowledge of the modern methods experienced postharvest loss, which was higher than those who had no knowledge (54\%). This indicates that awareness of improved technology did not necessarily have a positive effect on postharvest loss of cereals. From the focus group discussions a number of various reasons for not using improved technology emerged. Some farmers indicated that despite being aware of the existence of improved storage technologies, they did not utilize them because of non accessibility and unavailability. Other farmers said that the high cost of purchasing them was a prohibitive factor. The findings of this study are similar to those of a study in Nigeria, which found that despite dissemination of information on improved storage systems, some farmers did not utilize them due to other reasons such as high costs and non availability of resources and technology [31]. The results of the current study also concur with a study in West and Central Africa on adoption of improved technology, which showed that a key constraint to farmers use of triple layer plastics technology despite their awareness of them was due to local unavailability [32]. Thus while awareness of the benefits of improved storage technology may be high among farmers, households may not adopt them due to costs or non availability.

Table 2. Awareness of improved storage system and household postharvest cereal loss

\begin{tabular}{cccccccc}
\hline \multirow{2}{*}{$\begin{array}{c}\text { Distribution by } \\
\text { awareness of } \\
\text { improved storage }\end{array}$} & Frequency & Percent & & \multicolumn{2}{c}{$\begin{array}{c}\text { cereal } \\
\text { Loss }\end{array}$} & \multicolumn{2}{c}{$\begin{array}{c}\text { No cereal } \\
\text { loss }\end{array}$} \\
\cline { 5 - 8 } system & & & F & $\%$ & F & $\%$ \\
Yes & 264 & 77 & 172 & 65 & 92 & 35 \\
No & 79 & 23 & 43 & 54 & 36 & 46 \\
\hline Total & 343 & 100 & & & & \\
\hline
\end{tabular}

Source: Field survey data (2017)

\subsection{Adoption of Improved Storage Systems and Households Postharvest Cereal Loss}

Table 3 presents data on the adoption of improved storage and household postharvest cereal loss. From the table, it is clear that an overwhelming majority of the respondents (92\%) in Wikililye had not adopted the improved storage system. Only a small proportion (8\%) of the households utilized modern methods of storage, mainly the hermetic bags. These findings are similar to those of a an earlier study carried out in eastern region of 
Kenya among other regions, which showed that there was a very low rate of hermetic storage, plastics bag technologies usage, and adoption of the same was minimal [26]. From the current study it is evident that a majority of the respondents (76\%) who had utilized improved methods of cereal storage did not experience post harvest cereal losses compared to $34 \%$ of the respondents who had not adopted. The proportion of households experiencing post harvest cereal losses was higher for households, which had not adopted improved storage system compared to households, which had already adopted. The findings of the study are consistent with studies elsewhere, which found that hermetic storage bags were effective in reducing postharvest losses (storage losses less than 1\%) [33], a situation also observed during long distance (international) shipments. Similarly the current study findings are in agreement with the findings of studies in Uganda and Burkina Faso on the influence of improved postharvest management practices and the use of new technologies on postharvest loss of cereals [34]. The results of these studies revealed that irrespective of crop or storage period, the use of improved practices and new technologies resulted in about 98\% reduction in postharvest cereal loss. Thus utilization of improved storage facilities can result in significant reduction of postharvest cereal loss thereby contributing to improved food security.

Table 3. Adoption of improved storage and household postharvest cereal loss

\begin{tabular}{|c|c|c|c|c|c|c|}
\hline \multirow{2}{*}{$\begin{array}{l}\text { Distribution by } \\
\text { adoption of } \\
\text { improved storage } \\
\text { system }\end{array}$} & \multirow{2}{*}{ Frequency } & \multirow{2}{*}{ Percent } & \multicolumn{2}{|c|}{$\begin{array}{c}\text { cereal } \\
\text { Loss }\end{array}$} & \multicolumn{2}{|c|}{$\begin{array}{c}\text { No cereal } \\
\text { loss }\end{array}$} \\
\hline & & & $\mathrm{F}$ & $\%$ & $\mathrm{~F}$ & $\%$ \\
\hline Yes & 29 & 8 & 7 & 24 & 22 & 76 \\
\hline No & 314 & 92 & 208 & 66 & 106 & 34 \\
\hline Total & 343 & 100 & & & & \\
\hline
\end{tabular}

Source: Field survey data (2017)

\section{Conclusion}

The present study has revealed that farmers in Wikililye Location largely rely on traditional storage methods, which cannot guarantee protection against major storage pests of staple food such as maize; this has contributed to postharvest cereal losses. Further, the study reveals that awareness of improved storage systems does not necessarily positively impact postharvest cereal loss. This is because other factors such as economic ability and ease of availability have to be considered for farmers to adopt the improved storage technologies. In spite of the challenges that households face in the utilization of improved cereal management strategies, improved storage technology reduces postharvest cereal losses for the farmers who adopt them.

\section{Acknowledgements}

We wish to acknowledge South Eastern Kenya University for financially supporting this study. We also wish to acknowledge our study respondents in Wikililye for their invaluable contribution. Without them this study would not have succeeded.

\section{References}

[1] FAO. (2011b). Situation analysis: improving food safety in the maize value chain in Kenya (Report prepared for FAO by Prof. Erastus Kang'ethe College of Agriculture and Veterinary Science, University of Nairobi, September 2011.).

[2] Aulakh, J., Regmi, A., Fulton, J. R., Alexander, C. E., \& others. (2013). Estimating post-harvest food losses: Developing a consistent global estimation framework. In 2013 Annual Meeting, August 4-6, 2013, Washington, DC. Agricultural and Applied Economics Association. Retrieved from https://ideas.repec.org/p/ags/aaea13/150363.html

[3] Bala, B. K., Haque, M. A., Hossain, A., \&Majumdar, S. (2010). Post harvest loss and technical efficiency of rice, wheat and maize production system: assessment and measures for strengthening food security. Bangladesh Agricultural University, Final report CF. Retrieved from

http://fpmu.gov.bd/agridrupal/sites/default/files/CF6_of_08_B_K_Bala.pdf

[4] Majumder, S., Bala, B. K., Arshad, F. M., Haque, M. A., \& Hossain, M. A. (2016). Food security through increasing technical efficiency and reducing postharvest losses of rice production systems in Bangladesh. Food Security, 8(2), 361-374.

[5] Kumar, D., \&Kalita, P. (2017). Reducing Postharvest Losses during Storage of Grain Crops to Strengthen Food Security in Developing Countries. Foods, 6(1), 8.

[6] Grover, D. K., \& Singh, J. M. (2013). Post-harvest Losses in Wheat Crop in Punjab: Past and Present. Agricultural Economics Research Review, 26(2). Retrieved from

http://search.ebscohost.com/login.aspx?direct=true\&profile=ehost \&scope=site\&authtype $=$ crawler\&jrnl=09713441\&AN=93281682 \&h=oGK8ssXOFmkTiOkepKMU\%2F\%2FDpAkP\%2Fhx9i5ivsI1 PSKZffC0ufbzEYDJqsc5DdpqpCU6hNrl248UxefqCPTJvtdQ\%3 $\mathrm{D} \% 3 \mathrm{D} \& \mathrm{crl}=\mathrm{C}$

[7] Hell, K., Cardwell, K. F., Setamou, M., \&Poehling, H.-M. (2000). The influence of storage practices on aflatoxin contamination in maize in four agroecological zones of Benin, West Africa. Journal of Stored Products Research, 36(4), 365-382.

[8] Olayemi, F. F., Adegbola, J. A., Bamishaiye, E. I., \&Awagu, E. F. (2012). Assessment of postharvest losses of some selected crops in eight local government areas of rivers state, Nigeria. Asian Journal of Rural Development, 2(1), 13-23.

[9] Boxall, R. A. (2002). Damage and loss caused by the larger grain borer Prostephanustruncatus. Integrated Pest Management Reviews, 7(2), 105-121.

[10] Gabriel, A. H., \&Hundie, B. (2006). Farmers’ post-harvest grain management choices under liquidity constraints and impending risks: Implications for achieving food security objectives in Ethiopia. In Proceedings of the International Association of Agricultural Economists Conference. Citeseer. Retrieved from http://citeseerx.ist.psu.edu/viewdoc/download?doi=10.1.1.513.668 8\&rep=rep1\&type=pdf

[11] Mutungi, C., \&Affognon, H. (2013). Addressing food losses: status and way forward for postharvest research and innovations in Kenya. Retrieved from https://idl-bnc-idrc.dspacedirect.org/handle/10625/52222

[12] Republic of Kenya. (2007). Kenya Vision 2030. A competitive and prosperous nation: Nairobi. Kenya, Ministry of Planning and National Development in partnership, Kenya and Government of Finland.

[13] Odendo, M., De Groote, H., \&Odongo, O. M. (2001). Assessment of farmers' preferences and constraints to maize production in moist midaltitude zone of Western Kenya. In 5th International Conference of the African Crop Science Society, Lagos, Nigeria October (Vol. 2126, p. 2001).

[14] Recha, J., Kinyangi, J., \&Omondi, H. (2013). CLIMATE RELATED RISK AND OPPPORTUNITIES FOR AGRICULTURAL ADAPTION AND MITIGATION IN SEMIARID EASTERN KENYA. Retrieved from https://ccafs.cgiar.org/sites/default/files/assets/docs/climate_relate d_risk_and_opportunities.pdf 
[15] Abass, A. B., Ndunguru, G., Mamiro, P., Alenkhe, B., Mlingi, N., \&Bekunda, M. (2014). Post-harvest food losses in a maize-based farming system of semi-arid savannah area of Tanzania. Journal of Stored Products Research, 57, 49-57.

[16] Affognon, H., Mutungi, C., Sanginga, P., \&Borgemeister, C. (2015). Unpacking postharvest losses in sub-Saharan Africa: a meta-analysis. World Development, 66, 49-68.

[17] Kitinoja, L., Saran, S., Roy, S. K., \& Kader, A. A. (2011). Postharvest technology for developing countries: challenges and opportunities in research, outreach and advocacy. Journal of the Science of Food and Agriculture, 91(4), 597-603.

[18] Kaminski, J., \&Christiaensen, L. (2014). Post-harvest loss in subSaharan Africa-what do farmers say? Global Food Security, 3(3), 149-158.

[19] Tefera, T., \&Abass, A. B. (2012). Improved postharvest technologies for promoting food storage, processing, and household nutrition in Tanzania.

[20] World Bank, FAO, NRI. (2011). Missing Food: the case of Postharvest Grain Losses in Sub-Saharan Africa (Economic Sector Work No. 60371-AFR). Washington, DC.

[21] Shafiee-Jood, M., \&Cai, X. (2016). Reducing food loss and waste to enhance food security and environmental sustainability. Environmental Science \& Technology, 50(16), 8432-8443.

[22] Initiative, G. H., \& others. (2014). Global agricultural productivity report. Global Harvest Initiative. Washington DC Http://Www.Globalharvestinitiative.Org/Index.Php/MediaResources/Studies-Reports/. Accessed, 18.

[23] Kiaya, V. (2014). Post-harvest losses and strategies to reduce them. Action Contre La Faim (ACF). Retrieved from http://www.academia.edu/download/45278162/POST_HARVEST _LOSSES.pdf

[24] Kenya National Bureau of Statistics. (2009). Kenya Population and Housing Census: Population Density by Administrative Units. Nairobi: Author

[25] Omotilewa, O. J., Ricker-Gilbert, J., Ainembabazi, H., \& Shively, G. (2016). Impacts of Improved Storage Technology among Smallholder Farm Households in Uganda. In 2016 AAAE Fifth International Conference, September 23-26, 2016, Addis Ababa, Ethiopia. African Association of Agricultural Economists (AAAE).

[26] Ognakossan, K. E., Affognon, H. D., Mutungi, C. M., Sila, D. N., Midingoyi, S.-K. G., \&Owino, W. O. (2016). On-farm maize storage systems and rodent postharvest losses in six maize growing agro-ecological zones of Kenya. Food Security, 8(6), 1169-1189.
[27] Lathiya, S. B., Ahmed, S. M., Pervez, A., \& Rizvi, S. W. A. (2008). Food habits of rodents in grain godowns of Karachi, Pakistan. Journal of Stored Products Research, 44(1), 41-46.

[28] Rembold, F., Hodges, R., Bernard, M., Knipschild, H., \&Léo, O. (2011). The African Postharvest Losses Information System (APHLIS). European Union, Luxembourg. Retrieved from https://www.researchgate.net/profile/Felix_Rembold/publication/2 69405436_The_African_Postharvest_Losses_Information_System _APHLIS_An_innovative_framework_to_analyse_and_compute_ quantitative_postharvest_losses_for_cereals_under_different_farm ing_and_environmental_conditions/links/548aae150cf2d1800d7ab a6c/The-African-Postharvest-Losses-Information-SystemAPHLIS-An-innovative-framework-to-analyse-and-computequantitative-postharvest-losses-for-cereals-under-differentfarming-and-environmental-conditions.pdf

[29] Rugumamu, C. P. (2012). A Technique for Assessment of Intrinsic Resistance of Maize Varieties for the Control of Sitophilus zeamais (Coleoptera: Curculionidae). TaJONAS: Tanzania Journal of Natural and Applied Sciences, 3(1), 481-488.

[30] ANSAF. (2016). A Study on: Farmers' Access to Postharvest Technologies. Tanzania. Retrieved from

https://assets.helvetas.ch/downloads/study_on_farmers_access_to_ pht_gplp.pdf

[31] Onemolease, E. A. (2005). Impact of the Agricultural Development Programme (ADP) activities in arable crop production on rural poverty alleviation in Edo State, Nigeria. Unpublished Ph. D Thesis, University of Benin, Benin City Edo State, Nigeria 276p.

[32] Moussa, B., Abdoulaye, T., Coulibaly, O., Baributsa, D., \&Lowenberg-DeBoer, J. (2014). Adoption of on-farm hermetic storage for cowpea in West and Central Africa in 2012. Journal of Stored Products Research, 58, 77-86.

[33] Villers, P., Navarro, S., \& De Bruin, T. (2010). New applications of hermetic storage for grain storage and transport. In Proc. 10th International Working Conference on Stored Product Protection (pp. 446-452). Retrieved from http://www.grainpro.com/gpi/images/PDF/Commodity/FINAL_U nabridged_New_Applications_of_Hermetic_Storage_for_Grain_S torage_PU2044PV0310-3C.pdf

[34] Costa, S. J. (2014). Reducing food losses in Sub-Saharan Africa: improving post-harvest management and storage technologies of smallholder farmers. UN World Food Programme, Kampala, Uganda. 